\title{
Life threatening intracerebral haemorrhage following saw- scaled viper (Echis carinatus) envenoming-authenticated case report from Sri Lanka
}

\author{
Chathuranga Lakmal Fonseka', Vijayabala Jeevagan ${ }^{2,4^{*}}$ and Christeine Ariaranee Gnanathasan ${ }^{3}$
}

\begin{abstract}
Background: Echis carinatus (Saw scaled viper \{SSV\}) is a venomous snake found in the parts of Middle East and Central Asia. SSV envenoming is characterized by local swelling and coagulopathy. Various bleeding manifestations are commonly seen with SSV envenoming. In contrast to other part of Asia, saw scale viper envenoming has not been reported to cause life threatening haemorrhagic manifestations in Sri Lanka.

Case presentation: We report a 19 years old healthy boy who developed massive left temporo-parietal intra cerebral haemorrhage following Echis carinatus (Saw scaled viper) bite in Sri Lanka.

Conclusion: Although subspecies of SSV in Sri Lanka is regarded as a 'non lethal venomous snake', the occurrence of rare potentially fatal complications such as intracerebral haemorrhage should be considered in their management. This case report is intended to bring the awareness of this fatal complication of SSV envenoming in Sri Lanka.
\end{abstract}

\section{Background}

Echis carinatus (Saw scaled viper $\{\mathrm{SSV}\}$ ) is a venomous snake found in the parts of Middle East and Central Asia [1]. In Sri Lanka SSV is found in the dry coastal plains of northern, north-western and eastern provinces [2,3]. SSV envenoming is characterized by local swelling and coagulopathy. Various bleeding manifestations are commonly seen with SSV envenoming. Common bleeding manifestations include gingival bleeding, haematuria, epistaxis, haemoptysis and haematemesis. In a case series involving 48 SSV bite victims, $71 \%$ had coagulopathy as evidence by $20 \mathrm{~min}$ WBCT. Spontaneous bleeding occurred in 29\% and majority of them had either haematuria or haematemesis [4]. All the published case series of SSV bite in Sri Lanka failed to report any life threatening bleeding manifestations such as retoperitoneal, plero-pericardial or intracranial bleeding [4-6]. Fatalities due to SSV envenoming have not been reported in Sri Lanka. Therefore, in contrast

\footnotetext{
* Correspondence: jeevaganv@yahoo.com

${ }^{2}$ National Hospital, University medical unit, Colombo, Sri Lanka

${ }^{4}$ National Hospital of Sri Lanka, Regent Street, Colombo 8, Sri Lanka

Full list of author information is available at the end of the article
}

to other countries SSV envenoming in Sri Lanka is regarded as nonlethal and moderate venomous.

Here we report a 19 year old healthy boy who developed left massive temporo-parietal intra cerebral hemorrhage following SSV envenoming. Our case is the first case of intracerebral bleeding following saw- scaled viper envenoming in Sri Lanka. Pathophysiology of venom induced consumptive coagulopathy is discussed in order to understand the resultant coagulopathy from this envenoming.

\section{Case presentation}

A 19 years old healthy boy was bitten by a snake in his left foot while he was walking in his garden. The killed snake was brought to the hospital and identified as Echis carinatus (Figure 1) by the attending medical officer and one of the authors (CAG). On admission to the local hospital, there was mild local bleeding at the bite site, but there was no clinical evidence of systemic envenoming. Three hours after the bite he had developed progressive headache and his blood was found to be incoagulable by the 20 minutes Whole blood clotting test (20WBCT). He was treated immediately with 10 vials of polyvalent

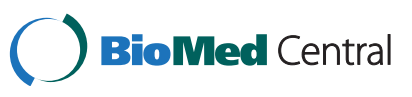




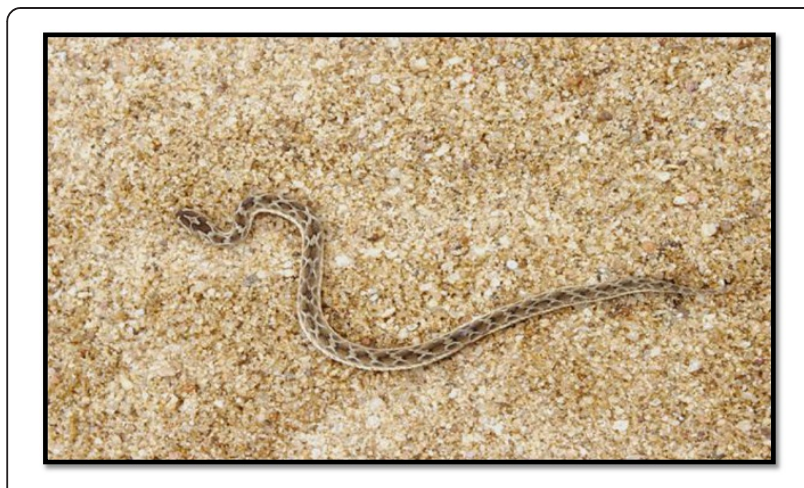

Figure 1 Example of a live saw- scaled viper.

antivenom serum (AVS) \{Vins Bioproduct\}, raised against Indian Daboia russelii, Echis carinatus, Naja naja and Bungarus caeruleus venoms, each vial was dissolved in 10 $\mathrm{ml}$ of sterile water and diluted with $200 \mathrm{ml}$ of normal saline to a total volume of $300 \mathrm{ml}$ and was infused intravenously over an hour to restore the coagulability. Despite of restoration of coagulability, the headache persisted throughout without any demonstrable neurological deficit.

Following day, he had developed right sided complete ptosis with fixed dilated pupil. On detection of these neurological features the boy was immediately transferred to the University Medical unit, National Hospital of Sri Lanka.

On admission to our unit, his Glasgow Coma Scale (GCS) was 13/15. Cranial nerve examination confirmed right sided complete ptosis with fixed dilated pupil. Fundoscopic examination failed to revealed papilloedema. Upper and lower limbs were neurologically normal. His blood pressure was 130/80 mm Hg with pulse rate of 66 beats $/ \mathrm{min}$ and respiratory rate was $14 / \mathrm{min}$. There was no evidence of external bleeding. The blood was coagulable by $20 \mathrm{WBCT}$. The urgent non-contrast CT brain showed a massive left temporo-parietal region intra-cerebral haemorrhage with intra-ventricular extension (Figure 2). His vital parameters and GCS were monitored regularly.

Laboratory investigations revealed a haemoglobin of $13.2 \mathrm{~g} / \mathrm{dl}$, total leukocyte count of 13,500 , with $80 \%$ neutrophils, platelet count of $178,000 / \mathrm{mm} 3$. Coagulation profile showed prothrombin time (PT) 18 seconds (control $12 \mathrm{~s}$ ) with INR of 1.44 thromboplastin time with kaolin (PTTK) was 38 seconds (control-35 s) and fibrinogen degradation products was $2.72 \mathrm{mg} / \mathrm{l}$ (Normal $-<0.20 \mathrm{mg} / \mathrm{l}$ ). The biochemical investigations including blood urea, serum creatinine, plasma glucose, serum bilirubin and transaminases were with in normal limit.

An urgent Digital Subtraction Angiography (DSA) of the intracranial vessel was performed and which was normal excluding the possibility of ruptured aneurysm or an arterio-venous malformation. Since his clinical

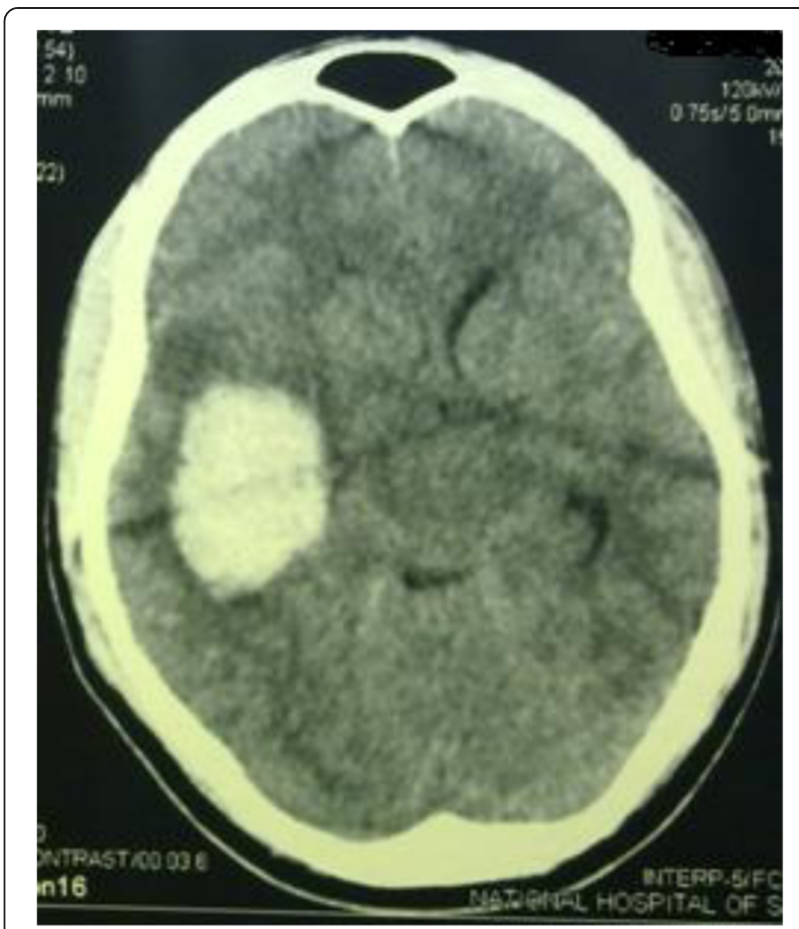

Figure 2 Non-contrast CT brain showing a massive left temporo-parietal region intra-cerebral haemorrhage.

parameters were improving, he was managed conservatively without any neurosurgical intervention. He was discharged home a week later in good health without any neurological deficit.

\section{Discussion and conclusion}

Saw- scaled viper venom is a highly complex mixture of a variety of biological substances including protein and non protein toxins $[7,8]$. Multiple mechanisms have been suggested for coagulopathy following SSV envenoming. The most common coagulopathy associated with snake bite envenoming is venom induced consumptive coagulopathy (VICC) [9].

A VICC result from the activation of the coagualation pathway in varied points by procoagulant toxins. SSV venom contains two metalloproteinases that are prothrombin activators namely ecarin and carinactivase [7,8]. Activation of prothrombin by these factors result in consumptive coagulopathy with variable deficiency in fibrinogen, factor V and factor VII [9]. Simultaneous injury to the blood vessel integrity increases the risk of bleeding. The venom also contains factor $\mathrm{X}$ activator and many other compounds which increases its capacity to cause coagulopathy such as platelet aggregation inhibitors [7-9]. VICC and direct endothelial injury due to haemorrhagin in the venom might be responsible for the near fatal intracerebral haemorrhage in our patient. VICC is characterized by prolonged $20 \mathrm{WBCT}, \mathrm{PT}$ and 
PTTK and a marked increase in fibrinogen degradation products.

Personal communication with many practicing physicians in the Island revealed that there is a wide variation in the treatment methods used in SSV envenoming. Because of the belief, that the Sri Lankan subspecies of SSV is never fatal to man, AVS is not used by all. Although subspecies of SSV in Sri Lanka is regarded as a 'non lethal venomous snake', the occurrence of rare potentially fatal complications such as intracerebral haemorrhage should be considered in their management. AVS should be administered promptly if features of systemic envenoming are present. In our patient neurological deficit was progressive despite the prompt use of AVS. It indicates either AVS was less effective in preventing progression of intracerebral haemorrhage or inadequate dose of AVS was used. It is essential to evaluate the effectiveness of AVS against specific subspecies of SSV in Sri Lanka, so that AVS should be used if it is beneficial only. The use of Fresh Frozen Plasma (FFP) in VICC remains controversial and only few studies investigating this issue. In a study included 167 cases of VICC following snake bite envenoming in Australia, showed AVS was ineffective in restoration of coagulopathy [10]. Interestingly FFP replacement was associated with faster recovery and reduced the risk of bleeding [10]. These findings should be confirmed in well designed randomized controlled trails in Sri Lankan Echis carinatus, before making any conclusions. This case report is intended to bring the awareness of this fatal complication of SSV envenoming in Sri Lanka.

\section{Consent}

Written informed consent was obtained from the patient for publication of this Case report and any accompanying images. A copy of the written consent is available for review by the Editor of this journal.

\section{Competing interests}

The authors declare that they have no competing interests.

\begin{abstract}
Authors' contributions
VJ and CLF carried out the literature search and drafted the manuscript; CAG did the critical revision for important intellectual content in the manuscript and given the final approval of the version to be published; all the authors read and approved the final manuscript.
\end{abstract}

\section{Author details}

'National Hospital Sri Lanka, University medical unit, Colombo, Sri Lanka. ${ }^{2}$ National Hospital, University medical unit, Colombo, Sri Lanka. ${ }^{3}$ Faculty of Medicine, University of Colombo, Colombo, Sri Lanka. ${ }^{4}$ National Hospital of Sri Lanka, Regent Street, Colombo 8, Sri Lanka.

Received: 17 September 2012 Accepted: 5 April 2013 Published: 8 April 2013

\section{References}

1. Warrell DA: Venoms and toxins of animals and plants. In Oxford Textbook of Medicine. Edited by Weatherall DJ, Leadingham JG, Warrell DA. Oxford: Oxford Medical Publications; 1983:635-642.

2. Deraniyagala PEP: A coloured Atlas of some vertebrates from Ceylon. Colombo, Ceylon: Government press; 1955.

3. De Silva A: Echis carinatus. In Snakes of Sri Lanka, a coloured atlas. Colombo: Vijitha Yapa Publications; 2009:116-117.

4. Gnanathasan A, Rodrigo C, Peranantharajah T, Coonghe A: Saw-scaled viper bites in Sri Lanka: is it a different subspecies? Clinical evidence from an authenticated case series. Am J Trop Med Hyg 2012 Feb, 86(2):254-257.

5. Kularatne SAM, Sivansuthan S, Medagedara SC, Maduwage K, de Silva A: Revisiting saw-scaled viper (Echis carinatus) bites in the Jaffna Peninsula of Sri Lanka: distribution, epidemiology and clinical manifestations. Trans R Soc Trop Med Hyg 2011, 105:591-5971.

6. Whitehall JS, Yarlini M, Arunthathy M, Varan M, Kaanthan M, Isaivanan M, Vanprasath M: Snake bites in north east Sri Lanka. Rural Remote Health 2007, 7:751

7. Cortelazzo A, Guerranti R, Bini L, Hope-Onyekwere N, Muzzi C, Leoncini R, Pagani R: Effects of snake venom proteases on human fibrinogen chains. Blood Transfus 2010, 8(Suppl 3):120-125.

8. Warrell DA, Davidson NMD, Greenwood BM, Ormerod LD, Pope HM, Watkins BJ, Prentice CR: Poisoning by bites of the saw-scaled or carpet viper (Echis carinatus) in Nigeria. Q J Med 1977, 46(181):33-62.

9. Isbister GK: Snakebite doesn't cause disseminated intravascular coagulation: coagulopathy and thrombotic microangiopathy in snake envenoming. Semin Thromb Hemost 2010, 36(4):444-451.

10. Isbister GK, Duffull SB, Brown SG, ASP Investigators: Failure of antivenom to improve recovery in Australian snakebite coagulopathy. QJM 2009, 102(8):563-568.

doi:10.1186/1471-227X-13-5

Cite this article as: Fonseka et al:: Life threatening intracerebral haemorrhage following saw- scaled viper (Echis carinatus) envenomingauthenticated case report from Sri Lanka. BMC Emergency Medicine 2013 13:5.

\section{Submit your next manuscript to BioMed Central and take full advantage of:}

- Convenient online submission

- Thorough peer review

- No space constraints or color figure charges

- Immediate publication on acceptance

- Inclusion in PubMed, CAS, Scopus and Google Scholar

- Research which is freely available for redistribution 